\title{
The Effects of Laparoscopic Sleeve Gastrectomy on Biochemical and Hematological Parameters in Short Term; Retrospective Review of Laboratory and Radiological Findings
}

\section{Hüseyin Akyol}

Altınbas University School of Medicine Bahcelievler Medical Park Hospital

Berrin Erok ( $\nabla$ drberrinerok@hotmail.com )

Prof Dr Cemil Tascıoglu City Hospital

\section{Research Article}

Keywords: laparoscopic sleeve gastrectomy, metainflammation, obesity, metabolic syndrome, neutrophillymphocyte ratio, platelet / lymphocyte ratio

Posted Date: August 27th, 2021

DOl: https://doi.org/10.21203/rs.3.rs-842270/v1

License: (c) (1) This work is licensed under a Creative Commons Attribution 4.0 International License.

Read Full License 


\section{Abstract}

Obesity, with its many associated diseases, is the fastest growing public health problem worldwide. Obesity related chronic inflammation is the main pathophysiological basis in many obesty related comorbidities. In obesity, hypertrophic growth of adipose tissue is associated with the stimulation of the secretion of inflammatory mediators such as tumor necrosis factor-alpha (TNF-a) and interleukin-6 (IL-6) $(2,3)$. Continued release of inflammatory mediators leads to chronic inflammation.Inflammatory markers such as neutrophil-lymphocyte ratio (NLR) and platelet / lymphocyte ratio (PLR), which are used as diagnostic and prognostic factors in infectious diseases, have been shown to play an important role in the prognostic evaluations in many diseases. The aim of this study is to retrospectively investigate the changes in these obesty related biochemical and hematological parameters 6 months after laparoscopic sleeve gastrectomy (LSG). In addition we also retrospectively reviewed the findings of abdominal ultrasonography (US) examinations in all patients and computed tomography (CT) findings in patients who had been performed, in terms of postoperative complications. In our study, the improvements in inflamatory markers in addition to glucose and lipid profiles have been showed with a possitive correlation parallel to the change in BMI.

\section{Introduction}

Obesity, with its many associated diseases, is the fastest growing public health problem worldwide. Obesity related chronic inflammation is the main pathophysiological basis in many obesty related comorbidities. Surgical treatment has been found to be an effective treatment method for obese patients with a body mass index (BMI) above $40 \mathrm{~kg} / \mathrm{m}^{2}$ and even for those having BMI between 35 and 39,9 $\mathrm{kg} / \mathrm{m}^{2}$ with concomitant diseases related to the obesity (1). In obesity, hypertrophic growth of adipose tissue is associated with the stimulation of the secretion of inflammatory mediators such as tumor necrosis factor-alpha (TNF-a) and interleukin-6 (IL-6) $(2,3)$. Continued release of inflammatory mediators leads to chronic inflammation. The increase in interleukin-6 (IL-6) causes an increase in the number of white blood cells (WBCs) in addition to the level of -reactive protein (CRP) $(2,4)$. Inflammatory markers such as neutrophil-lymphocyte ratio (NLR) and platelet / lymphocyte ratio (PLR), which are used as diagnostic and prognostic factors in infectious diseases, have been shown to play an important role in the prognostic evaluations in many diseases such as cardiovascular diseases, COPD, pneumonia, rheumatic diseases, different types of cancers and also obesity (5-8). Furthermore, they have proven to be useful markers for the prognosis of postoperative complications (9-11). The aim of this study is to retrospectively investigate the changes in these obesty related biochemical and hematological parameters 6 months after laparoscopic sleeve gastrectomy (LSG). In addition we also retrospectively reviewed the findings of abdominal ultrasonography (US) examinations in all patients and computed tomography (CT) findings in patients who had been performed, in terms of postoperative complications.

\section{Materials And Methods}




\section{Study population}

149 consequtive patients who underwent LSG at Altınbaş University Bahçelievler Medical Park Hospital between January 2015 and June 2020 were included in the study, except the patients under 18 years of age. All of the patients received vitamin B12, iron, and folic acid supplements in the first 6 months after the surgery. The files of the study patients were retrospectively investigated. The demographic characteristics of the patients, obesity-related chronic diseases (diabetes mellitus type II, hypertension and dyslipidemia), body mass indexes and blood tests performed in the last 1 month before the surgery, and blood tests performed in 6 months after the surgery were investigated. In addition, abdomianl ultrasonography (US) and computed tomography (CT) performed 6 months after the surgery were rewieved in terms of any complications, if any. Pre-operative and 6 months post-operative biochemical parameters (fasting blood glucose, insulin, homeostatic model assessment of cell function and insulin resistance [HOMA-IR], glycated hemoglobin [HbA1c], total cholesterol [TC], high density lipoprotein [HDL], low density lipoprotein [LDL], very low density lipoprotein [VLDL], triglyceride [TG], aspartate aminotransferase [AST], alanine aminotransferase [ALT], white blood cell count [WBC], hemoglobin level [HGB], hematocrit level [HCT], patelet count [PLT], neutrophil count [NEU] and lymphocyte count [LYM]), NLR and PLR were statistically compared.

\section{Statistical analysis}

IBM SPSS Statistics 22 (IBM SPSS, Turkey) program was used in the statistical evaluation of findings obtained in the study. The suitability of the parameters to the normal distribution was evaluated by Kolmogorov-Smirnov and Shapiro Wilks tests. In the evaluation of the study data, in addition to descriptive statistical methods (mean, standard deviation, frequency), paired sample t test was used for the postoperative comparison of the parameters showing normal distribution compared to the preoperation in the comparison of the quantitative data, and the Wilcoxon sign test was used for the comparison of the parameters that did not show normal distribution. Significance was evaluated at the $p$ $<0.05$ level.

\section{Results}

The study was conducted with a total of 149 patients including 85 (57\%) female and 64 (43\%) male patients with average age of $42.47 \pm 12.15$ years (range between 19 to 72 ) who had undergone obesity surgery. 47 of the cases (31.5\%) had type 2 diabetes, 61 (40.9\%) had hypertension, and $66(44.3 \%)$ had dyslipidemia. Postoperative changes observed in the study parameters compared to the preoperative values were shown in the Table 1. 
Table 1

Postoperative changes observed in the study parameters compared to the preoperative values

\begin{tabular}{|c|c|c|c|c|c|c|}
\hline & \multirow{2}{*}{$\begin{array}{l}\text { preoperative } \\
\text { mean } \pm S D\end{array}$} & \multirow{2}{*}{$\begin{array}{l}\text { postoperative } \\
\text { mean } \pm S D\end{array}$} & \multirow{2}{*}{$\begin{array}{l}\text { difference } \\
\text { mean } \pm \\
S D\end{array}$} & \multicolumn{3}{|c|}{$\begin{array}{l}95 \% \text { confidence interval } \\
\text { of the difference }\end{array}$} \\
\hline & & & & $\begin{array}{l}\text { Lower } \\
\text { limit }\end{array}$ & $\begin{array}{l}\text { Upper } \\
\text { limit }\end{array}$ & $\mathbf{p}$ \\
\hline weight & $134,31 \pm 17,4$ & $94,17 \pm 11,44$ & $\begin{array}{l}40,14 \pm \\
8,34\end{array}$ & 38,79 & 41,49 & ${ }^{1} 0,000 *$ \\
\hline BMI & $44,96 \pm 5,07$ & $31,53 \pm 3,31$ & $\begin{array}{l}13,44 \pm \\
2,64\end{array}$ & 13,01 & 13,86 & ${ }^{1} 0,000 *$ \\
\hline FBG & $\begin{array}{l}120,87 \pm \\
53,36(102)\end{array}$ & $\begin{array}{l}93,52 \pm 14,77 \\
(91)\end{array}$ & $\begin{array}{l}27,34 \pm \\
54,43\end{array}$ & 18,53 & 36,15 & ${ }^{2} 0,000 *$ \\
\hline Insulin & $\begin{array}{l}22,92 \pm 12,39 \\
(20,1)\end{array}$ & $\begin{array}{l}7,43 \pm 2,85 \\
(7,2)\end{array}$ & $\begin{array}{l}15,49 \pm \\
12,63\end{array}$ & 13,44 & 17,53 & ${ }^{2} 0,000 *$ \\
\hline HOMA-IR & $\begin{array}{l}6,9 \pm 4,87 \\
(5,2)\end{array}$ & $\begin{array}{l}1,73 \pm 0,79 \\
(1,6)\end{array}$ & $\begin{array}{l}5,17 \pm \\
4,87\end{array}$ & 4,38 & 5,96 & ${ }^{2} 0,000 *$ \\
\hline $\mathrm{HbA} 1 \mathrm{c}$ & $6,97 \pm 2(6,2)$ & $\begin{array}{l}5,89 \pm 0,68 \\
(5,7)\end{array}$ & $\begin{array}{l}1,08 \pm \\
2,22\end{array}$ & 0,73 & 1,44 & ${ }^{2} 0,000$ * \\
\hline Triglyceride & $\begin{array}{l}162,48 \pm 91,4 \\
(142)\end{array}$ & $\begin{array}{l}102,08 \pm 24,11 \\
(99)\end{array}$ & $\begin{array}{l}60,4 \pm \\
95,44\end{array}$ & 44,95 & 75,85 & ${ }^{2} 0,000$ * \\
\hline VLDL & $\begin{array}{l}32,53 \pm 18,31 \\
(28)\end{array}$ & $\begin{array}{l}20,40 \pm 4,79 \\
(20)\end{array}$ & $\begin{array}{l}12,13 \pm \\
19,10\end{array}$ & 9,04 & 15,23 & ${ }^{2} 0,000$ * \\
\hline $\begin{array}{l}\text { Total } \\
\text { cholesterol }\end{array}$ & $214,15 \pm 40,3$ & $180,26 \pm 21,22$ & $\begin{array}{l}33,89 \pm \\
44,58\end{array}$ & 26,67 & 41,11 & ${ }^{1} 0,000 *$ \\
\hline LDL & $\begin{array}{l}136,84 \pm \\
31,47\end{array}$ & $111,79 \pm 18,26$ & $\begin{array}{l}25,05 \pm \\
36,2\end{array}$ & 19,19 & 30,91 & ${ }^{1} 0,000 *$ \\
\hline HDL & $41,18 \pm 8,92$ & $46,49 \pm 8,39$ & $\begin{array}{l}-5,32 \pm \\
11,58\end{array}$ & $-7,19$ & $-3,44$ & ${ }^{1} 0,000 *$ \\
\hline ALT & $\begin{array}{l}46,26 \pm 42,76 \\
(31)\end{array}$ & $\begin{array}{l}20,71 \pm 10,4 \\
(16)\end{array}$ & $\begin{array}{l}25,55 \pm \\
42,67\end{array}$ & 18,64 & 32,46 & ${ }^{2} 0,000 *$ \\
\hline \multicolumn{7}{|c|}{${ }^{1}$ Paired samples $t$ test ${ }^{2}$ Wilcoxon sign test ${ }^{*} p<0.05$} \\
\hline \multicolumn{7}{|c|}{$\begin{array}{l}\text { Normally distributed parameters are shown as mean } \pm S D \text {, non-normally distributed parameters are } \\
\text { shown as mean } \pm S D \text { (median). }\end{array}$} \\
\hline \multicolumn{7}{|c|}{ SD: standard deviation } \\
\hline \multicolumn{7}{|c|}{ BMI:body mass index } \\
\hline \multicolumn{7}{|c|}{ FBG:fasting blood glucose } \\
\hline $\begin{array}{l}\text { Normally dis } \\
\text { shown as Me }\end{array}$ & $\begin{array}{l}\text { Ited paramete } \\
\text { tSD (median) }\end{array}$ & e shown as $\mathrm{M}$ & $\pm S D$, non & nally & ed pa & are \\
\hline
\end{tabular}




\begin{tabular}{|c|c|c|c|c|c|c|}
\hline \multirow[b]{2}{*}{ AST } & \multirow{2}{*}{$\begin{array}{l}\text { preoperative } \\
32,57 \pm 28,64 \\
(22)\end{array}$} & \multirow{2}{*}{$\begin{array}{l}\text { postoperative } \\
\begin{array}{l}20,32 \pm 9,08 \\
(18)\end{array}\end{array}$} & \multirow{2}{*}{$\begin{array}{l}\text { difference } \\
12,25 \pm \\
27,68\end{array}$} & \multicolumn{3}{|c|}{$\begin{array}{l}95 \% \text { confidence interval } \\
\text { of the difference }\end{array}$} \\
\hline & & & & 7,77 & 16,73 & ${ }^{2} 0,000 *$ \\
\hline WBC & $\begin{array}{l}9,34 \pm 3,17 \\
(8,9)\end{array}$ & $\begin{array}{l}7,26 \pm 1,35 \\
(7,3)\end{array}$ & $2,08 \pm 3,5$ & 1,51 & 2,64 & ${ }^{2} 0,000 *$ \\
\hline $\mathrm{HB}$ & $13,72 \pm 1,48$ & $13,52 \pm 1,35$ & $0,2 \pm 1,61$ & 0,06 & 0,46 & ${ }^{1} 0,128$ \\
\hline HCT & $41,5 \pm 4,12$ & $40,49 \pm 3,97$ & $\begin{array}{l}1,01 \pm \\
4,52\end{array}$ & 0,28 & 1,74 & ${ }^{1} 0,007 *$ \\
\hline PLT & $\begin{array}{l}279,64 \pm \\
69,47(270)\end{array}$ & $\begin{array}{l}251,68 \pm 56,92 \\
(240)\end{array}$ & $\begin{array}{l}27,96 \pm \\
75,85\end{array}$ & 15,68 & 40,24 & ${ }^{2} 0,000 *$ \\
\hline Neutrophil & $\begin{array}{l}6,25 \pm 3,40 \\
(5,2)\end{array}$ & $\begin{array}{l}4,17 \pm 1,17 \\
(4,2)\end{array}$ & $\begin{array}{l}2,08 \pm \\
3,57\end{array}$ & 1,50 & 2,65 & ${ }^{2} 0,000 *$ \\
\hline Lymphocytet & $2,66 \pm 0,8$ & $2,24 \pm 0,71$ & $\begin{array}{l}0,42 \pm \\
1,01\end{array}$ & 0,26 & 0,59 & ${ }^{1} 0,000 *$ \\
\hline NLR & $2,59 \pm 2,03(2)$ & $\begin{array}{l}2,03 \pm 0,78 \\
(2,1)\end{array}$ & $\begin{array}{l}0,56 \pm \\
2,15\end{array}$ & 0,21 & 0,91 & ${ }^{2} 0,013^{*}$ \\
\hline PLR & $\begin{array}{l}113,96 \pm \\
41,47(104,3)\end{array}$ & $\begin{array}{l}120,28 \pm 36,48 \\
(121,8)\end{array}$ & $\begin{array}{l}-6,32 \pm \\
44,55\end{array}$ & $-13,53$ & 0,89 & ${ }^{2} 0,071$ \\
\hline \multicolumn{7}{|c|}{${ }^{1}$ Paired samples $t$ test ${ }^{2}$ Wilcoxon sign test ${ }^{*} p<0.05$} \\
\hline \multicolumn{7}{|c|}{$\begin{array}{l}\text { Normally distributed parameters are shown as mean } \pm S D \text {, non-normally distributed parameters are } \\
\text { shown as mean } \pm S D \text { (median). }\end{array}$} \\
\hline \multicolumn{7}{|c|}{ SD: standard deviation } \\
\hline \multicolumn{7}{|c|}{ BMI:body mass index } \\
\hline \multicolumn{7}{|c|}{ FBG:fasting blood glucose } \\
\hline \multicolumn{7}{|c|}{$\begin{array}{l}\text { Normally distributed parameters are shown as Mean } \pm S D \text {, non-normally distributed parameters are } \\
\text { shown as Mean } \pm S D \text { (median). }\end{array}$} \\
\hline
\end{tabular}

The decrease in BMI seen after the operation compared to the pre-operative BMI was statistically significant ( $p: 0.000 ; p<0.05)$. The decreases in the average level of fasting blood glucose, insulin, HOMAIR, $\mathrm{HbA} 1 \mathrm{c}$ seen after the operation compared to the pre-operative values were statistically significant (p:0.000; $p<0.05)$.

The decreases in the level of triglyceride, VLDL, total cholesterol, LDL seen after the operation compared to the pre-operative values were statistically significant ( $p: 0.000 ; p<0.05)$.

The increase in the level of HDL seen after the operation compared to the pre-operative values was statistically significant ( $\mathrm{p}: 0.001 ; \mathrm{p}<0.05)$. 
The decreases in the level of ALT, AST seen after the operation compared to the pre-operative were statistically significant ( $p: 0.000 ; p<0.05)$.

The decrease in the level of hematocrit seen after the operation compared to the pre-operative value, although is not very much, was found to be statistically significant $(p: 0.007 ; p<0.05)$.

No statistically significant change was observed in hemoglobin level after the operation compared to the pre-operative value $(p>0.05)$.

The decrease seen seen in WBC, platelet, neutrophil, lymphocyte after the operation compared to the preoperative values were statistically significant $(p: 0.000 ; p<0.05)$.

The decrease seen in the level of neutrophil lymphocyte ratio (NLR) after the operation compared to the pre-operative value was statistically significant $(p: 0.013 ; p<0.05)$.

No statistically significant change was observed in platelet lymphocyte ratio (PLR) after the operation compared to the pre-operative value $(p>0.05)$.

All patients had at least one abdominal US 6 months after the surgery and newly developed gallstones was established in 6 of the patients when compared with their preoperative abdominal US reports. The gallstones were a few or multiple small mainly noncalcified Stones (Fig. 1). In 9 patients abdomian CT had been performedd for the evaluation of gastric leakage but in none of the patients neather gastic leak nor any perigastric collection/hemorrhage was established.

\section{Discussion}

Obesity is characterized by the increased adipose tissue which in turn is associated with increased release of pro-inflammatory mediators resulting in a chronic, sterile, systemic inflammatory state via the role of both innate and adaptive immune responses. This is named as metabolic inflammation or metainflammation and is thought as the major factor in the pathophysiology of obesity related comorbidities known as metabolic syndrome (MS) (12). Surgical treatment of obesity has been shown to be affected in not only weight loss but also in the improvement of metabolic profile. Following surgical treatment of obesity, decrease in the ongoing inflammatory process has been shown with various serum inflammatory markers, particularly $\operatorname{CRP}(13,4)$. LSG is one of the most effective bariatric surgery method in the treatment of obesity. In a study conducted on 21 obese patients who underwent LSG, it has been reported that CRP showed a significant decrease at 3 months after surgery despite no significant differences of IL- 6 and TNF-a were established. In this study, HbA1c, TG, and TC were also improved (15).The most obvious decrease in inflammatory parameters were reported particularly in the short term results during the first 6 months. However, a retrospective cohort study including 163 obese patients demonstrated the reduction in the metainflammation up to 4 years after the bariatric surgery by reporting complete normalization of hs-CRP in $84.0 \%$ of patients in 4 years The intensity of weight loss was also reported to have a significant linear effect on change in WBC and change in hs-CRP at long term follow- 
up (16). Improvements in blood glucose and lipid profile (TC, LDL-C and TG) is important to reduce major cardiovascular risk factors and it has been well documented in various studies within the 6 months after the surgical intervention $(13,17)$. In our study, a significant decrease in TC, LDL and also VLDL has been achieved at the 6th month following LSG. Furthermore, HDL level was also increased significantly in our patients.Inflammatory biomarkers such as CRP, WBC, fibrinogen and procalcitonin have also been studied regarding their potential to determine perioperative morbidity following various obesity surgeries. In addition some of them are investigated in terms of determining early postoperative complications. In a study investigating biomarkers that might be useful to predict gastric leak before its clinical presentation in 151 patients who underwent LSG reported that NLR and procalcitonin detected gastric leak with significantly higher sensitivity and specificity than CRP, fibrinogen and WBC (18). In our study we did not observed any gastric leak. On the other hand, LSG may cause nutritional deficiencies and may lead to anemia. In a study including 494 obese patients who underwent LSG and followed up to 2 years, it was shown that proper vitamin and mineral supplementation therapy keep hematological parameters within the normal range (19). In our patient although not so much, some statistically significant decrease in the htc levels have been observed but the hb levels were not decreased.

\section{Conclusion}

In our study, the improvements in inflamatory markersin addition to glucose and lipid profiles have been showed with a possitive correlation parallel to the change in BMI. We found that NLR decreased significantly and no significant change was observed in PLR 6 months after LSG. More studies are needed to understand the potential role of NLR and PLR ratios in the pathophysiology of obesity surgery and related complications.

\section{Declarations}

Ethics approval and consent for participate: Ethics approval has been obtained from Altınbas University School of Medicine Bahcelievler Medical Park Hospital Research Ethics Committee. Written informed consent has been taken from the patiens.

All methods were performed in accordance with the relevant guidelines and regulations.

Availability of data and materials: The data sets used and/or analysed during the current study are available from the corresponding author upon reasonable request.

Competing interests: none.

Funding: none.

Authors' contributions:

Consept: Hüseyin Akyol, Berrin Erok, 
Design: Berrin Erok, Hüseyin Akyol

Data collection and processing: Berrin Erok, Hüseyin Akyol

Analysis: Hüseyin Akyol, Berrin Erok

Literature search: Berrin Erok, Hüseyin Akyol

Writing: Berrin Erok

\section{References}

1. Editors. Brunicardi F, \& Andersen D.K., \& Billiar T.R., \& Dunn D.L., \& Kao L.S., \& Hunter J.G., \& Matthews J.B., \& Pollock R.E.(Eds.), (2019). Schwartz's Principles of Surgery, $11^{\text {th }}$ ed., vol. 2, chapter 27, McGraw-Hill.

2. Nishimura S, Manabe I, Nagai R. Adipose tissue inflammation in obesity and metabolic syndrome. Discov Med. 2009 Aug;8(41):55-60. PMID: 19788868.

3. Mraz M, Haluzik M. The role of adipose tissue immune cells in obesity and low-grade inflammation. J Endocrinol. 2014;222(3): R113-27.

4. Lau DC, Dhillon B, Yan H, Szmitko PE, Verma S. Adipokines: molecular links between obesity and atheroslcerosis. Am J Physiol Heart Circ Physiol. 2005 May;288(5):H2031-41.

5. Severity of Helicobacter pylori Infection with Peripheral Blood Neutrophil to Lymphocyte Ratio and Mean Platelet Volume. Euroasian J Hepatogastroenterol. 2017 Jan-Jun;7(1):11-16.

6. Yoon NB, Son C, Um SJ. Role of the neutrophil-lymphocyte count ratio in the differential diagnosis between pulmonary tuberculosis and bacterial community-acquired pneumonia. Ann Lab Med. 2013 Mar;33(2):105-10.

7. Ethier JL, Desautels D, Templeton A, Shah PS, Amir E. Prognostic role of neutrophil-to-lymphocyte ratio in breast cancer: a systematic review and meta-analysis. Breast Cancer Res. 2017 Jan $5 ; 19(1): 2$.

8. Gasparyan AY, Ayvazyan L, Mukanova U, Yessirkepov M, Kitas GD. The Platelet-to-Lymphocyte Ratio as an Inflammatory Marker in Rheumatic Diseases. Ann Lab Med. 2019 Jul;39(4):345-357.

9. Vaughan-Shaw PG, Rees JR, King AT. Neutrophil lymphocyte ratio in outcome prediction after emergency abdominal surgery in the elderly. Int J Surg. 2012;10(3):157-62.

10. Simpson G, Saunders R, Wilson J, Magee C. The role of the neutrophil:lymphocyte ratio (NLR) and the CRP:albumin ratio (CAR) in predicting mortality following emergency laparotomy in the over 80 age group. Eur J Trauma Emerg Surg. 2018 Dec;44(6):877-882.

11. Halazun KJ, Aldoori A, Malik HZ, Al-Mukhtar A, Prasad KR, Toogood GJ, Lodge JP. Elevated preoperative neutrophil to lymphocyte ratio predicts survival following hepatic resection for colorectal liver metastases. Eur J Surg Oncol. 2008 Jan;34(1):55-60. 
12. Vivekanandhan Aravindhan, Haridoss Madhumitha, "Metainflammation in Diabetic Coronary Artery Disease: Emerging Role of Innate and Adaptive Immune Responses", Journal of Diabetes Research, vol. 2016, Article ID 6264149, 10 pages, 2016.

13. Tedesco AK, Biazotto R, Gebara TS, Cambi MP, Baretta GA. PRE- AND POSTOPERATIVE IN BARIATRIC SURGERY: SOME BIOCHEMICAL CHANGES. Arq Bras Cir Dig. 2016;29Suppl 1(Suppl 1):67-71.

14. Salman MA, Salman AA, Nafea MA, et al. Study of changes of obesity-related inflammatory cytokines after laparoscopic sleeve gastrectomy. ANZ J Surg. Blackwell Publishing. 2019;89:1265-9.

15. Si, Q., Gu, Yt., Liu, Dg. et al. The Effect of Laparoscopic Sleeve Gastrectomy on TNF-a, IL-6, and CRP in Obese Patients. Indian J Surg (2020).

16. Lautenbach, A., Stoll, F., Mann, O. et al. Long-Term Improvement of Chronic Low-Grade Inflammation After Bariatric Surgery. OBES SURG (2021)

17. Bilecik T. Metabolic Effects of Sleeve Gastrectomy with Transit Bipartition in Obese Females with Type 2 Diabetes Mellitus: Results After 1-Year Follow-up. Obes Surg. 2019 Mar;29(3):805-810.

18. Romano L, Mattei A, Colozzi S, Giuliani A, Cianca G, Lazzarin G, Fiasca F, Carlei F, Schietroma M. Laparoscopic sleeve gastrectomy: A role of inflammatory markers in the early detection of gastric leak. J Minim Access Surg. 2020 Sep 12.

19. Kyio NH, Turgut S, Ozkan T, Cetin G. Evolution of Hematological Parameters During the First 2 Years After Laparoscopic Sleeve Gastrectomy: Results of a Retrospective Study. Obes Surg. 2020 Jul;30(7):2606-2611.

\section{Figures}




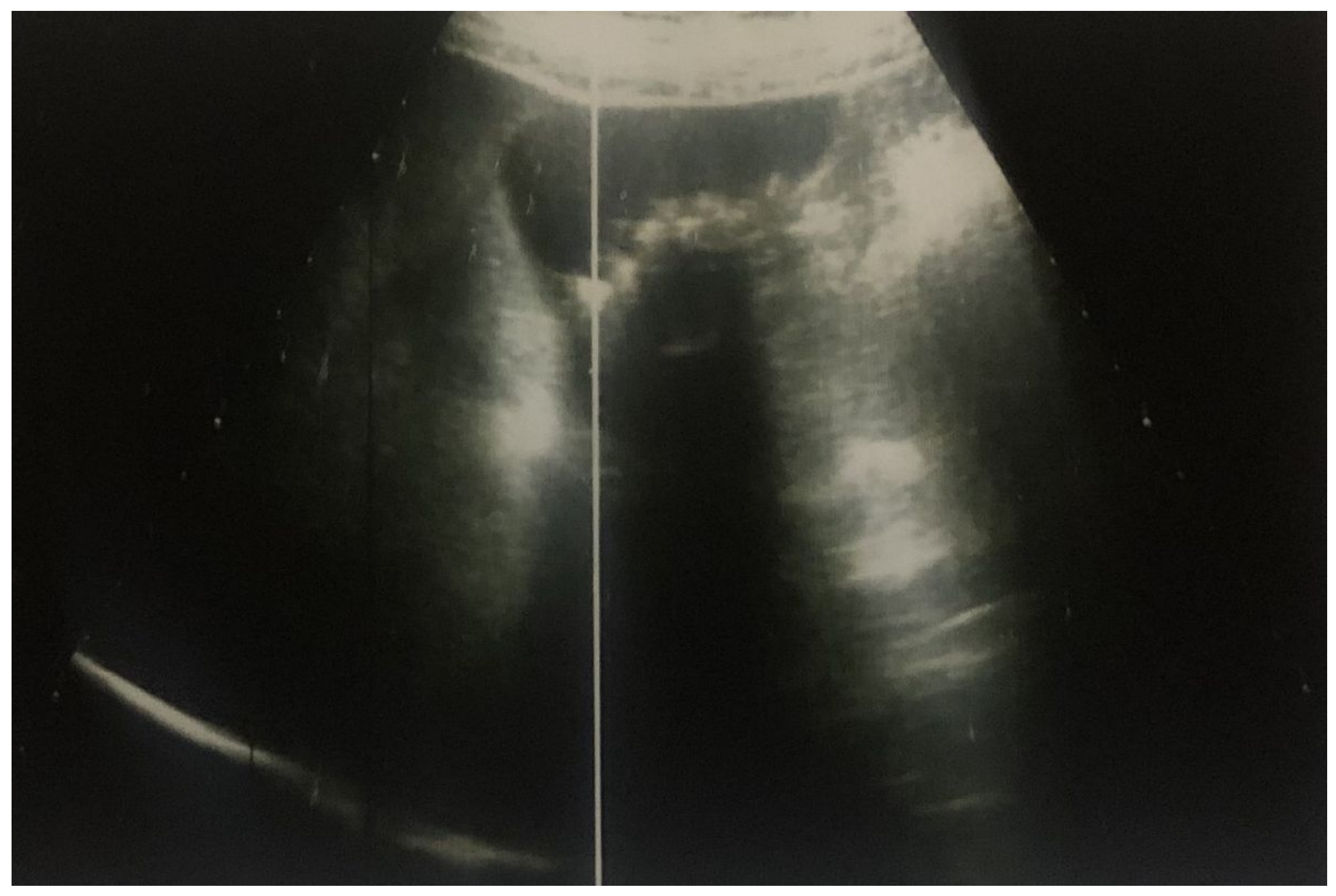

\section{Figure 1}

US image of multiple small milimetric gallstones that developed 6 months after LSG. 